\title{
Biomechanical performance of a bicycle helmet design on a six-year-old head impact protection
}

\author{
Bei Li, Haiyan Li, Shihai Cui, \\ Lijuan He and Shijie Ruan*
}

Centre for Injury Biomechanics and Vehicle Safety, Tianjin University of Science and Technology,

Tianjin 30022, China

Email: libei2014@mail.tust.edu.cn

Email: lihaiyan@tust.edu.cn

Email: shihaicui@tust.edu.cn

Email: helijuan@tust.edu.cn

Email: jruan36@yahoo.com

*Corresponding author

\begin{abstract}
A previously developed and validated 6-year-old (6YO) Finite Element (FE) human head model was used to evaluate the biomechanical performance of a new bicycle helmet design for children. The cushion structure of the new helmet design is made of honeycomb paperboard and corrugated paperboard instead of Expanded Polystyrene (EPS) foam. Simulation results showed that the EPS foam helmet can effectively resist external shocks in a short period. However, based on biomechanical responses of the $6 \mathrm{YO}$ head model, honeycomb and corrugated paperboard helmets also had a promising cushioning performance. From the drop test of the head-helmet model simulations, the effects of paperboard thickness and material parameters on the helmet protection efficiency were further investigated. It was concluded that the EPS foam helmet can be replaced with honeycomb/corrugated paperboard helmets which are made of more environmental friendly manufacturing materials.
\end{abstract}

Keywords: bicycle helmet model; human head model; injury biomechanics; corrugated; honeycomb.

Reference to this paper should be made as follows: Li, B., Li, H., Cui, S., He, L. and Ruan, S. (2020) 'Biomechanical performance of a bicycle helmet design on a six-year-old head impact protection', Int. J. Vehicle Safety, Vol. 11, No. 3, pp.197-213.

\section{Introduction}

Head injury is the leading cause of fatality and disability in the USA (CDC, 2003). It poses a special challenge in the paediatric population, as early-age injury may lead to mental problems that can last for a life-time along with heavy economic burdens to the family and society. The most frequent causes of children's head injuries are motorvehicle accidents, falls, and maltreatment (Hyde et al., 2014). 
Numerous human head FE models have been developed over the past decades to study blunt traffic accidents (Iwamoto et al., 2015); injury in boxing (Hernandez et al., 2016); falls (Coats et al., 2007); contact sports (Ji et al., 2014; Ji and Zhao, 2015); and blast-induced injuries (Sevagan et al., 2013). Few of these studies focused on paediatric head injury, among which most paediatric head FE models age ranged from 0 to 3 years (Klinich et al. 2002; Coats et al., 2007; Roth et al., 2007; Ruan et al., 2012; Cui et al., 2015). All these studies provided encouraging insights for further investigating the head injury problems (McPherson and Kriewall, 1980; Davis et al., 2012; Li et al., 2015, 2016; Coats et al., 2007; Li et al., 2013a; Zhou et al., 2016; Li et al., 2013b).

Helmets have been recommended to be used whenever it is possible to reduce the risk of head injury. According to the Centre for Disease Control and Prevention, the probability of children's head injury and loss of consciousness decreased by $63 \%$ and $86 \%$, respectively, when helmets were used. The Expanded Polystyrene (EPS) foamed plastic constitutes an absorption layer of the helmet; it has a good property of water resistance. However, EPS produces a very strong chemical substance as waste which is difficult to degrade and when incinerated produces a large number of toxic gases that endanger the human immune system and animal-plant ecosystems. On the contrary, cushion structure made from honeycomb paperboard and corrugated paperboard can also provide high cushioning performance while have large benefits of environmental protection.

Given these considerations, this study is the first innovative proposal to use corrugated and honeycomb structures made from paperboard in cushioning to develop a new safety helmet for children riding. The practicability and protective performance of paperboard helmet were analysed. Conclusions from this study can provide theoretical guidance for the development and manufacture of paperboard helmets.

\section{Methods and materials}

\subsection{Model description}

\subsubsection{Helmet}

The geometry of the helmet shell (including out shell and inner shell) and foam was provided by a manufacturer in a CAD file. The two parts of the helmet then were prepared to mesh into three finite element models with cushioning structure material made of EPS, honeycomb paperboard, and corrugated paperboard, respectively, by using Hypermesh software. The comfort liner is not included in the model as it is considered not to influence the headform response during impact. The outer shell and inner shell were meshed with shell elements with a thickness varying from $2.7 \mathrm{~mm}$ to $3.5 \mathrm{~mm}$ according to the considered helmet area. A specific attention is applied to the cushioning layer as its geometry is quite complicated. These layers are meshed with solid elements. The solid elements shared common nodes with honeycomb shell and corrugated shell. These models are illustrated in Figure 1, namely EPS foam, honeycomb paperboard and corrugated paperboard helmets. The thicknesses of these layers range from $13 \mathrm{~mm}$ for the chin to $20 \mathrm{~mm}$ for the vertex area. 
Figure 1 Finite element models of children helmet (a) EPS (b) corrugated (c) honeycomb

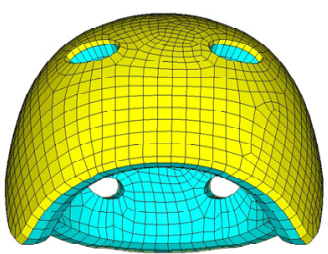

(a)

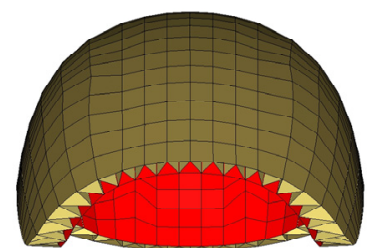

(b)

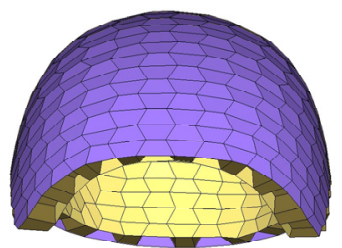

(c)

\subsubsection{Human head model}

In this study, a 6-year-old child head FE model which was developed and validated by Tianjin University of Science and Technology (Ruan et al., 2012) was used to study the shock absorption of three bicycle helmet designs, as illustrated in Figure 2. For the paediatric head model, subject-specific CT images (acquired for medical purposes unrelated to the present study) from a local hospital were obtained to derive the skull geometry. Data access was approved by the Institutional Review Board at the Tianjin University of Science and Technology.

Figure 2 Head (a) and brain (b) FE models representing 6-year-old children

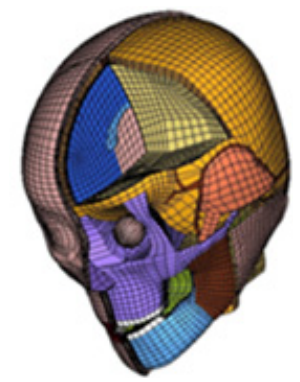

(a)

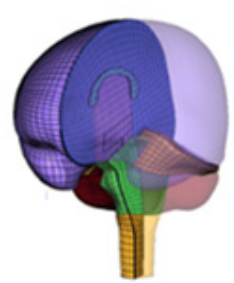

(b)

The brain anatomical regions included the cerebrum, the cerebellum, the brainstem, the diencephalon, ventricles, and the corpus callosum, and they were modelled using hexahedral elements. The models also included the flax and the tentorium, and these were represented by quadrilateral shell elements.

The skull was developed using hexahedral elements. The meningeal membranes and the Cerebral Spinal Fluid (CSF) between the brain and skull were modelled as hexahedral solid elements by sharing nodes with the brain outer surface and skull inner surface, similarly to other head models (Takhounts et al., 2008; Ji and Zhao, 2015). The models also include facial bones, the maxilla, the mandible, the scalp and the eye structure. 


\subsection{Material properties}

\subsubsection{Helmet model}

The EPS foam has a density of $83 \mathrm{~kg} / \mathrm{m}^{3}$ (Mills and Gilchrist, 2008), and it was modelled with the constitutive material model which is only defined by the compressive stressstrain curve of EPS (MAT-63-CRUSHABLE-FOAM from LS-Dyna material library) (Ghajari et al., 2009; Cernicchi et al., 2008). Paper and paperboard generally exhibit anisotropic and non-linear mechanical material behaviour (Mäkelä and Östlund, 2003). The orthotropic material parameters of honeycomb paperboard and corrugated paperboard were obtained by calculating the point of linear phase of material stress-strain curve, as illustrated in Tables 1 and 2 (Yuping, 2014). The outer shell of the bicycle helmet is usually made from Polycarbonate (PC). An isotropic linear elastic model was chosen to simulate the mechanical behaviour of the PC. It was assumed that all helmet models have the same shell material properties because the in-mould bonding between helmet shell and liner prevents proper removal of the shell without damaging the helmet. The density, Young's modulus and Poisson ratio of the PC used in all material models of shell were $1200 \mathrm{~kg} / \mathrm{m}^{3}, 2.2 \mathrm{GPa}$ and 0.37, respectively (Fernandes et al., 2013).

Table 1 Material parameters of honeycomb structure cushioning paperboard

\begin{tabular}{ccccccccc}
\hline$E_{x}(M p a)$ & $E_{y}(M p a)$ & $E_{z}(M p a)$ & $G_{x y}(M p a)$ & $G_{Y Z}(M p a)$ & $G_{x z}(M p a)$ & $\mu_{x y}$ & $\mu_{y z}$ & $\mu_{x z}$ \\
\hline 2.75 & 3.58 & 2.8 & 1.21 & 0.1 & 0.05 & 0.33 & 0.01 & 0.01 \\
\hline
\end{tabular}

Table 2 Material parameters of corrugated structure cushioning paperboard

\begin{tabular}{ccccccccc}
\hline$E_{x}(M p a)$ & $E_{y}(M p a)$ & $E_{z}(M p a)$ & $G_{x y}(M p a)$ & $G_{y z}(M p a)$ & $G_{x z}(M p a)$ & $\mu_{x y}$ & $\mu_{y z}$ & $\mu_{x z}$ \\
\hline 1.7 & 5 & 0.85 & 1.13 & 0.14 & 0.03 & 0.5 & 0.01 & 0.01 \\
\hline
\end{tabular}

\subsubsection{Head model}

There is a considerable paucity of mechanical properties concerning the evolution of brain tissue with age due to the lack of experimental test data. In this study, therefore, the $6 \mathrm{YO}$ children brain material properties and brain-skull boundary conditions were referred to that of Simulated Injury Monitor (SIMon) (Takhounts et al., 2008), as summarised in Table 3 .

The skulls were defined as rigid because acceleration is directly applied to the skull; this paper was not showed in the reference list.

\subsection{Simulation tests}

\subsubsection{Effect of cushioning structure on helmet protection efficiency}

Drop test simulations were performed to evaluate the effect cushioning structure on energy absorption. The 6YO head model coupling with the helmet models were released from a height of $30 \mathrm{~cm}$, and were dropped onto a flat aluminium surface. The orientation of the head was set to vertically drop to the plate with the forehead region facing downward. Von-Mises stress, strain, and contact force of the helmet models were used to 
investigate the effect of cushioning structure of EPS foam, honeycomb paperboard and corrugated paperboard on helmet protection efficiency.

Table 3 Material models and properties used in 6YO children head FE model

\begin{tabular}{|c|c|c|}
\hline Components & Material type & Material properties \\
\hline & & $\rho=1040 \mathrm{~kg} / \mathrm{m}^{3}$ \\
\hline Cerebrum & & $K=558.47 \mathrm{MPa}$ \\
\hline Cerebellum & Kelvin-Maxwell Viscoelastic & $G_{0}=0.00166 \mathrm{MPa}$ \\
\hline \multirow[t]{3}{*}{ Brain stem } & & $G_{I}=9.28 \mathrm{e}-04 \mathrm{MPa}$ \\
\hline & & $\beta=16.95$ \\
\hline & & $\rho=1130 \mathrm{~kg} / \mathrm{m}^{3}$ \\
\hline \multirow[t]{4}{*}{ Falx \& Tentorium } & Elastic & $E=31.5 \mathrm{MPa}$ \\
\hline & & $v=0.45$ \\
\hline & & $\rho=1050 \mathrm{~kg} / \mathrm{m}^{3}$ \\
\hline & & $K=4.966 \mathrm{MPa}$ \\
\hline \multirow[t]{4}{*}{ CSF } & Kelvin-Maxwell Viscoelastic & $G_{0}=0.1 \mathrm{MPa}$ \\
\hline & & $G_{I}=0.02 \mathrm{MPa}$ \\
\hline & & $\tau=0.01$ \\
\hline & & $\rho=35,200 \mathrm{~kg} / \mathrm{m}^{3}$ \\
\hline \multirow[t]{2}{*}{ Skull } & Rigid & $E=6900 \mathrm{MPa}$ \\
\hline & & $v=0.3$ \\
\hline
\end{tabular}

Notes: $\quad \rho=$ Density, $K=$ Bulk Modulus, $G_{0}=$ Short Time Modulus, $G_{I}=$ Long Time Shear Modulus, $\beta$ and $\tau=$ Decay Constant, $E=$ Young's Modulus, $\nu=$ Poisson's Ratio

\subsubsection{Effect of paperboard thickness and material properties on helmet protection efficiency}

Studies have shown that the height of children's bicycles ranges from $435 \mathrm{~mm}$ to $635 \mathrm{~mm}$ and the sitting height of children aged 6-7 is around $680 \mathrm{~mm}$. Therefore, in this study, the honeycomb paperboard helmet-head model was dropped by $30 \mathrm{~cm}, 60 \mathrm{~cm}$, $90 \mathrm{~cm}$ and $120 \mathrm{~cm}$, respectively, to investigate the protection efficiency of paperboard helmet at the different drop height. Based on the drop height of $30 \mathrm{~cm}$, then, the influence of paperboard thickness and elastic moduli on the brain response was investigated with honeycomb structure helmet model. During simulation, the thickness of paperboard varied from $4.8 \mathrm{~mm}$ to $8.8 \mathrm{~mm}$. And a parametric study was done with elastic modulus of the paperboard varied from 0.1 to 10 times of its base value.

\subsubsection{Drop test reconstruction}

In simulations, head model dropped onto stone-tile surface at the height of $120 \mathrm{~cm}$ with use of a honeycomb paperboard helmet. Four typical impact locations around occipitalparietal area were simulated to account for the uncertainty of the contact location. The peak head acceleration and contact force were compared to the results of head drop test without helmet. 


\subsection{Contact and boundary conditions}

Before simulation test, the head model fitted with helmet models. An automatic surfaceto-surface contact option was defined between head and inner shell, outer shell and plate, with a friction coefficient of 0.4 and 0.2 , respectively. The helmet model was allowed to move freely and no other constraints were placed on helmet.

Five helmet model-predicted responses were considered as the helmet cushioning performance predictors, including compression, contact force, acceleration, strain, and Von-Mises stress. Head element-wise Von-Mises stress and intracranial pressure during the entire simulation, regardless of the time of occurrence, were extracted for each simulation. An additional linear regression was performed using intracranial pressure, Von-Mises stress and shear stress as the single independent variable, and their performances were compared in terms of coefficients of determination $\left(R^{2}\right)$. The nonlinear dynamic finite element analysis software LS-DYNA was used to perform the analysis.

\section{Results}

\subsection{Effect of cushioning structure on helmet protection efficiency}

The compression of three baseline helmet models is $1.4 \mathrm{~mm}$ for the EPS foam, $2.98 \mathrm{~mm}$ for the honeycomb paperboard, and $5.3 \mathrm{~mm}$ for the corrugated paperboard, respectively. From Figure 3, it is evident that the EPS foam helmet yielded lower linear acceleration than those of two paperboard helmets because of the lower density of the EPS foam. The three helmet models yielded nearly identical effective strain (0.098 for EPS foam, 0.11 for honeycomb paperboard, and 0.10 for corrugated paperboard) as seen in Figure 4. It is observed from Figure 5 that the EPS foam helmet model sustained the highest Von-Mises stress response.

Figure 3 The time-history of helmet acceleration

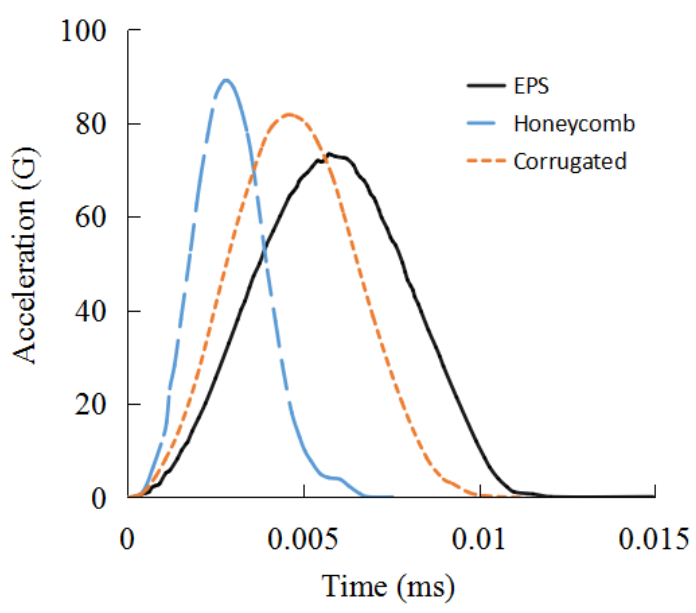


Figure 4 Effective strain contour of helmet (a) EPS foam helmet (b) and (c) honeycomb and corrugated paperboard helmet

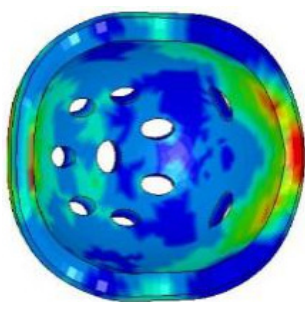

(a)

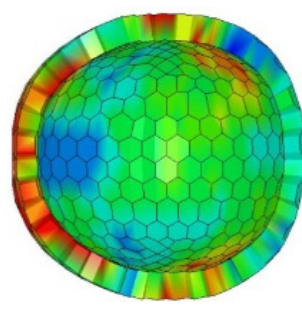

(b)

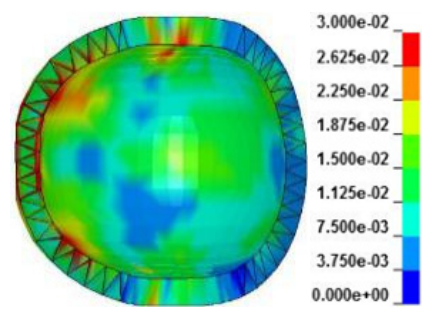

(c)

Figure 5 Von-Mises stress (MPa) contour of helmet when impact force attained the peak value (a) EPS foam helmet (b) and (c) honeycomb and corrugated paperboard helmet

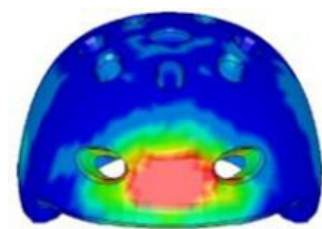

(a)

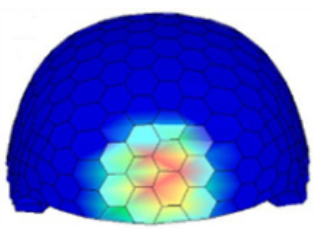

(b)

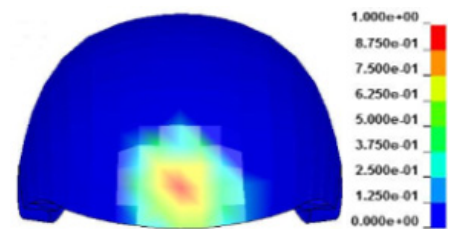

(c)

When three baseline helmet models were coupled with the 6YO human head model, Von-Mises stress magnitudes of the brain with the use of honeycomb and corrugated paperboard helmets yielded nearly identical stresses $(0.0031 \mathrm{MPa}$ and $0.0033 \mathrm{MPa}$, respectively). However, the head-EPS model exhibited lower $(15 \%)$ stress $(0.0028 \mathrm{MPa})$. The whole brain Von-Moses stress distributions of the three head models were largely similar in the cerebrum with large stress in the brainstem, but different in the corpus callosum with substantial stress presented in the head with two paperboard helmet models as seen in Figure 6.

Figure 6 Von-Mises stress (MPa) contour of brain (a) EPS foam helmet (b) and (c) honeycomb and corrugated paperboard helmet

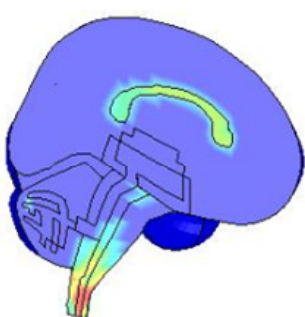

(a)

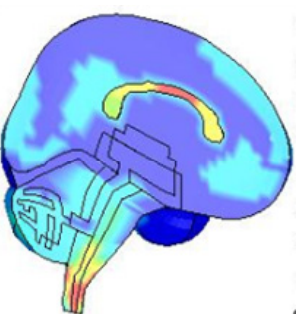

(b)

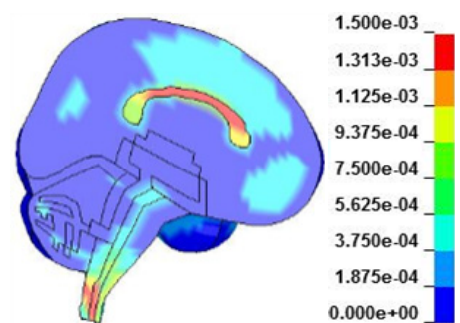

(c)

With identical impact velocity, the head with EPS helmet model yielded lower pressure than that of two paperboard helmets $(0.11 \mathrm{MPa}$ for EPS, $0.16 \mathrm{MPa}$ and $0.24 \mathrm{MPa}$ for 
honeycomb and corrugated paperboard helmets). The pressure gradient distributions of the head-EPS model was were similar to the head-honeycomb model with large pressure in the frontal. However, it dramatically differed in the cerebrum region with headcorrugated model yielded overestimation as seen Figure 7.

Figure 7 Intracranial pressure (MPa) contour (a) EPS foam helmet (b) and (c) honeycomb and corrugated paperboard helmet

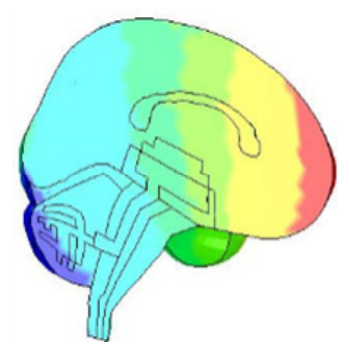

(a)

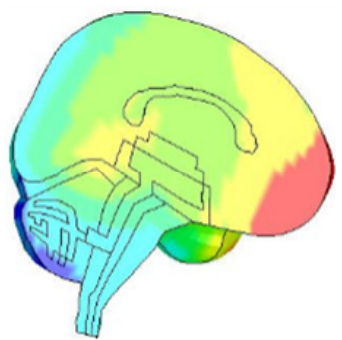

(b)

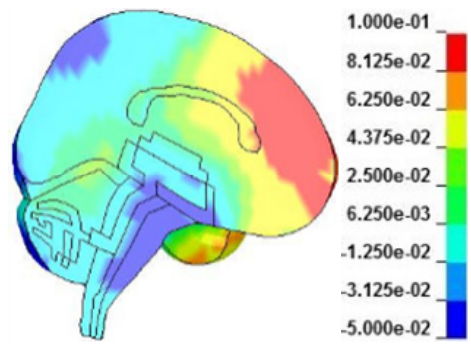

(c)

\subsection{Effect of paperboard thickness and material properties on helmet protection efficiency}

In general, the compression of helmet decreased by about $10 \%$ as the thickness of paperboard increased by $1 \mathrm{~mm}$ (see Figure 8). It is indicated that the protection efficiency of the helmet can be improved by increasing the thickness of paperboard. Firstly, the linear regression from Figure 9 suggested a significant relationship between paperboard thickness and Von-Mises stress of the helmet. Besides that, the thickness of paperboard has the highest correlation with head FE stresses for Von-Mises stress and shear stress $\left(R^{2}=0.96\right.$ and 0.97 as showed in Figures $10(\mathrm{c})$ and $\left.10(\mathrm{~d})\right)$, but not for coup and contrecoup pressures, as seen in Figures 10(a) and 10(b). From Figures 11 and 12 we can see that intracranial pressure and Von-Mises stress distributions in the brain was largely similar in the cerebrum with maximum value occurred in the impact region and brainstem.

Figure 8 Helmet displacement-time history curve at different paperboard thickness

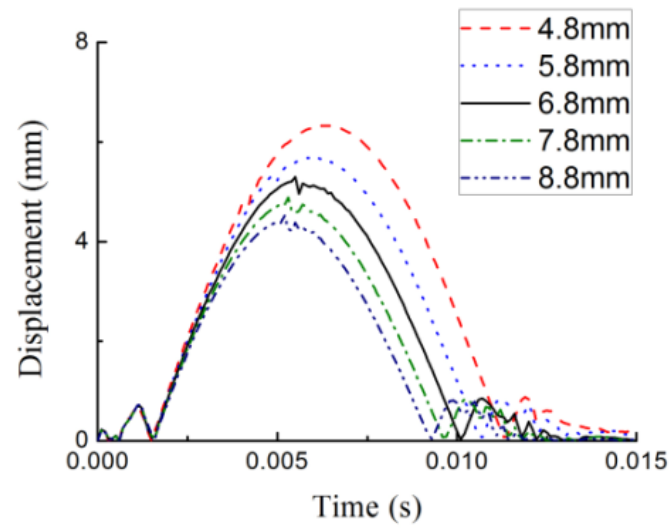


Figure 9 Scatter plots showing correlations between helmet Von-Mises stress and paperboard thickness

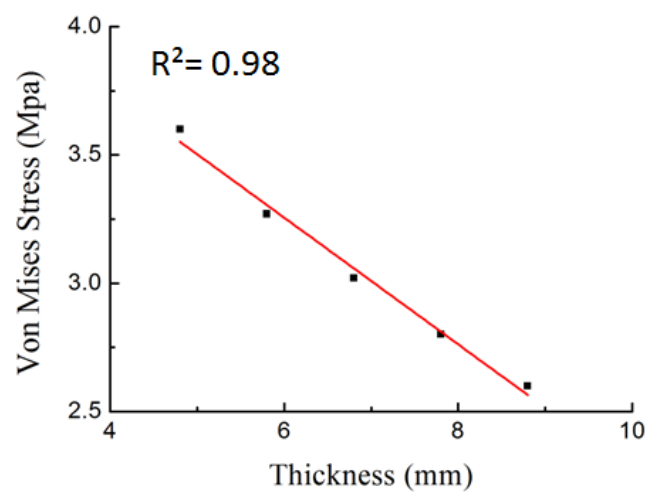

Figure10 Scatter plots showing correlations between biomechanical responses of brain and paper thickness (a) coup intracranial pressure (b) contrecoup intracranial pressure (c) Von-Mises stress (d) Maximum shear stress

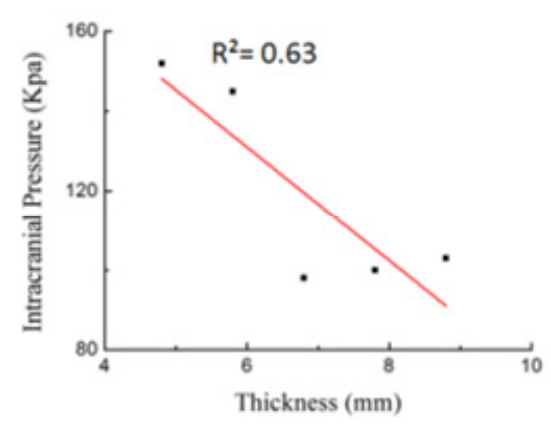

(a)

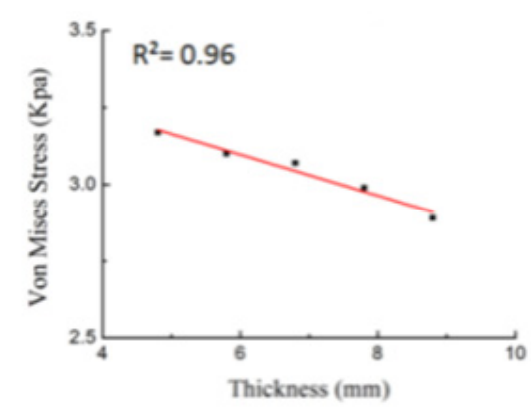

(c)

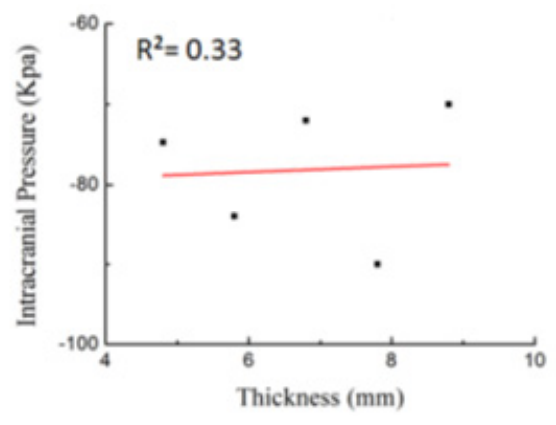

(b)

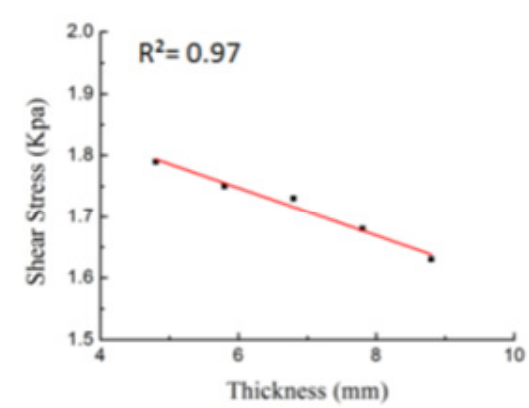

(d) 
Figure 11 Intracranial pressure (MPa) contour at different paper thickness (a) $4.8 \mathrm{~mm}$ (b) $5.8 \mathrm{~mm}$ (c) $6.8 \mathrm{~mm}$ (d) $7.8 \mathrm{~mm}(\mathrm{e}) 8.8 \mathrm{~mm}$

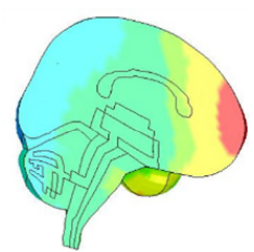

(a)

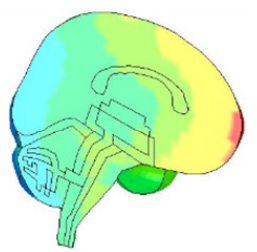

(b)

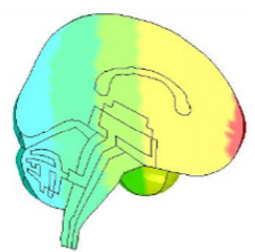

(c)

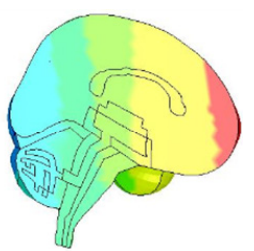

(d)

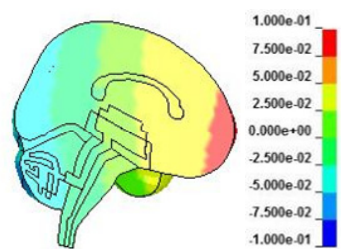

(e)

Figure 12 Von-Mises stress $(\mathrm{MPa})$ contour at different paper thickness (a) $4.8 \mathrm{~mm}$ (b) $5.8 \mathrm{~mm}$ (c) $6.8 \mathrm{~mm}$ (d) $7.8 \mathrm{~mm}$ (e) $8.8 \mathrm{~mm}$

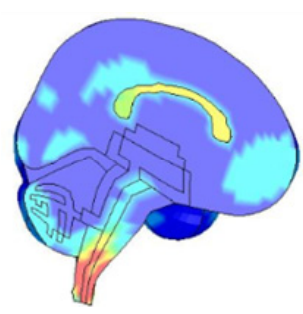

(a)

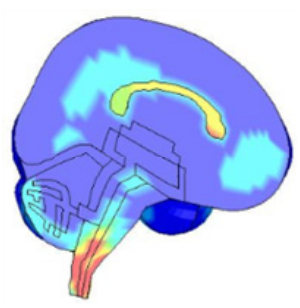

(b)

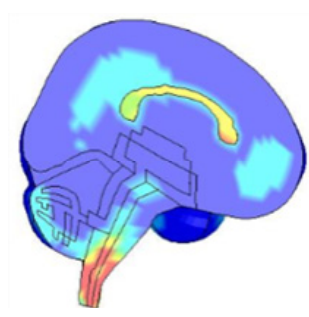

(c)

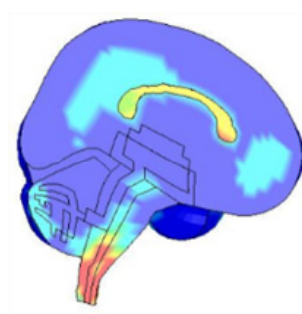

(d)

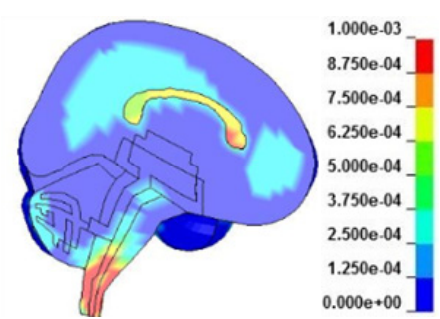

(e)

Model simulations were performed with the elastic modulus of paperboard varied from $0.1 \mathrm{E}$ to $10 \mathrm{E}$ of its base value. The compression of the helmet seen in Figure 13 shows the helmet compression was inversely proportional to elastic modulus of paperboard. On the contrary, the Von-Mises stress of the helmet increased with the elastic modulus of 
paperboard as shown in Figure 14. Most energy was absorbed by the helmet due to its high deformability. Therefore, it can be seen that the energy absorption performance of the helmet is highly sensitive to the elastic modulus of paperboard. Intracranial pressures, Von-Mises stresses and shear stresses of the brain increased with the elastic modulus of helmet paperboard as seen in Figure 15. However, the pattern of the stress distributions of the $6 \mathrm{YO}$ head model shows no proportionate behaviour with varying elastic modulus. It remained similar in cerebrum with large intracranial pressure and Von-Mises stress presented in the impact region and brainstem as seen in Figures 16 and 17. When the elastic modulus is reduced by five or ten times, the brain experienced the same distributions. When the elastic modulus exceeded $5 \mathrm{E}$ and $10 \mathrm{E}$, changes in intracranial pressure and Von-Mises stress were very significant. The brain stress distributions dramatically differed in the cerebrum with substantial higher occurred in the corpus callosum.

Figure 13 Comparison of helmet displacement resulted different elastic moduli of paper

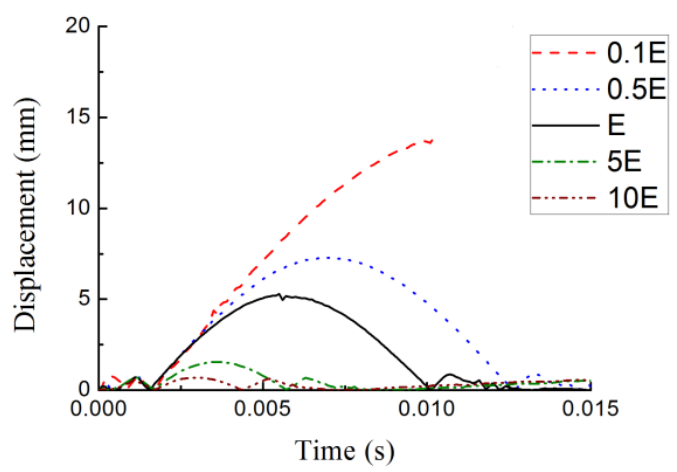

Figure 14 Scatter plots showing correlations between helmet Von-Mises stress and paper elastic modulus

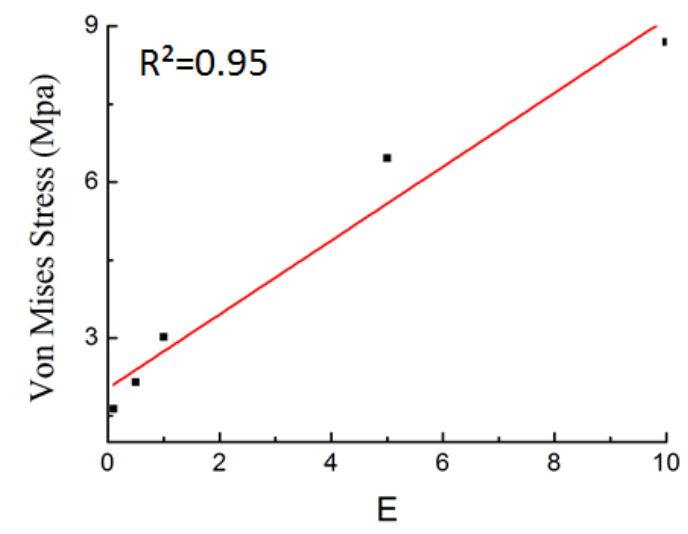


Figure 15 Scatter plots showing correlations between biomechanical responses of brain and paper elastic moduli (a) Coup intracranial pressure (b) Contrecoup intracranial pressure (c) Von-Mises stress (d) Maximum shear stress

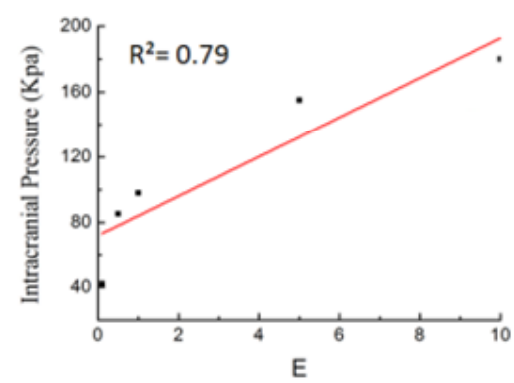

(a)

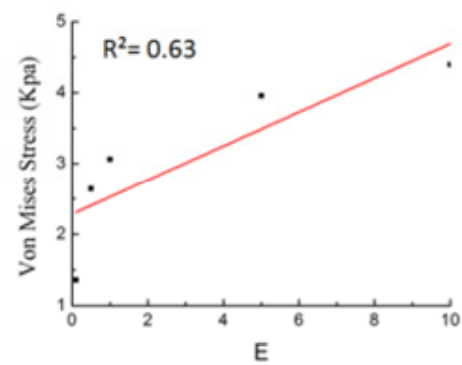

(c)

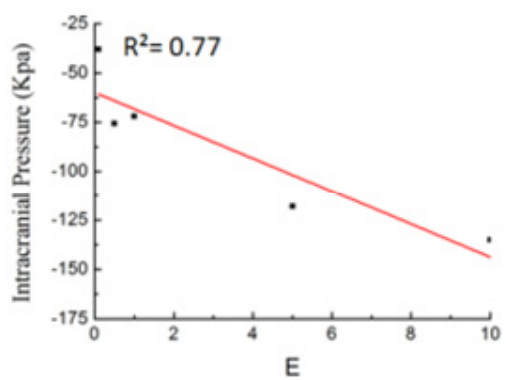

(b)

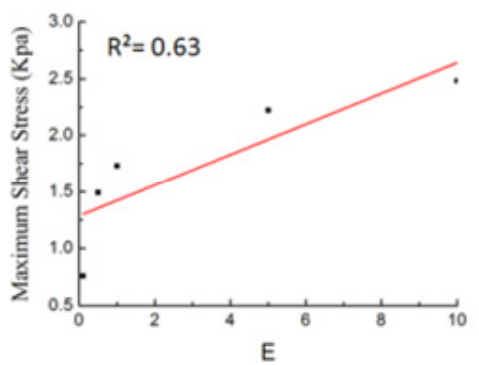

(d)

Figure16 Intracranial pressure $(\mathrm{MPa})$ contour at different paper elastic moduli (a) $0.1 \mathrm{E}$ (b) $0.5 \mathrm{E}$ (c) $\mathrm{E}$ (d) $5 \mathrm{E}$ (e) $10 \mathrm{E}$

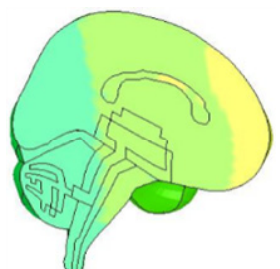

(a)

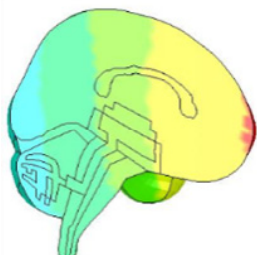

(b)

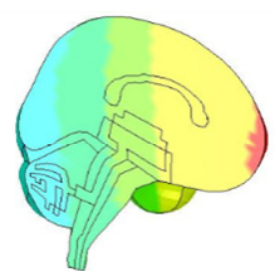

(c)

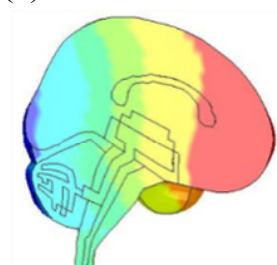

(d)

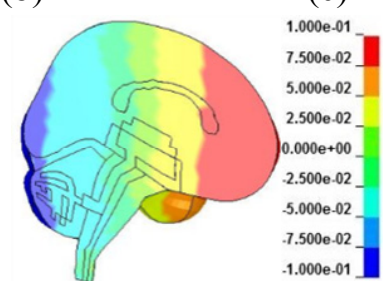

(e) 
Figure 17 Brain Von Mises stress (MPa) contour at different paper elastic moduli (a) $0.1 \mathrm{E}$ (b) $0.5 \mathrm{E}$ (c) $\mathrm{E}$ (d) $5 \mathrm{E}$ (e) $10 \mathrm{E}$

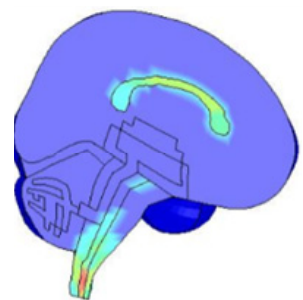

(a)

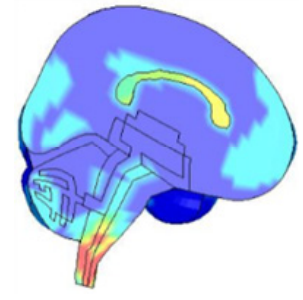

(b)

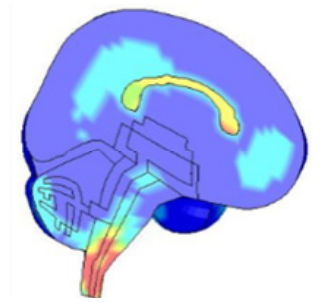

(c)

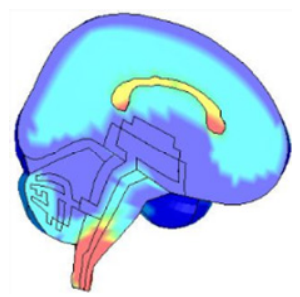

(d)

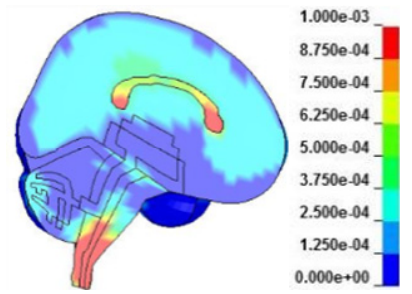

(f)

\subsection{Bicycling falls reconstruction}

In this section, the head was dropped from $120 \mathrm{~cm}$ in four typical impact locations to mimic the fall from a bicycle. The Von-Mises stress of helmet model is $5.85 \mathrm{MPa}$ (Frontal), 4.38 MPa (Vertex), 4.88 MPa (Occipital) and 4.2 MPa (Parietal), respectively. From Figure 18, it can be found that the impact region of helmet model experienced the highest stress and deformation. However, the honeycomb structure was not crushed.

For brain biomechanical responses, it can be seen that the largest stress occurred in the brainstem (Frontal view), the corpus callosum (Vertex view), the corpus callosum and the brainstem (Occipital and Parietal views) as seen in Figure19 which is the contour plots of Von-Mises stresses and in Figure 20 which is shear stress contour plots. It is suggested that the injury risk in the corpus callosum and brainstem is higher when the head falls from a height of $120 \mathrm{~cm}$. Besides that, it is obvious that in the forehead drop simulation test, the brain experienced the lowest stress. Compared with the results of the head drop test without a helmet, the biomechanical response of the head is dramatically reduced when the head uses the paperboard helmet model. As illustrated in table 4, head accelerations in four impact locations were reduced by $28.2 \%$ (Frontal), $1.4 \%$ (Vertex), 29.6\% (Occipital) and 12.8\% (Parietal), respectively. The contact force of the head was reduced by 21.2\% (Frontal), 5.4\% (Vertex), 27.7\% (Occipital), 11.8\% (Parietal), respectively. It is concluded that the paperboard honeycomb riding helmet can significantly reduce the risk of head injury for children. 
Figure 18 Von-Mises stress (MPa) contour of honeycomb helmet at drop height of $120 \mathrm{~cm}$ (a) Frontal (b) Vertex (c) Occipital (d) Parietal

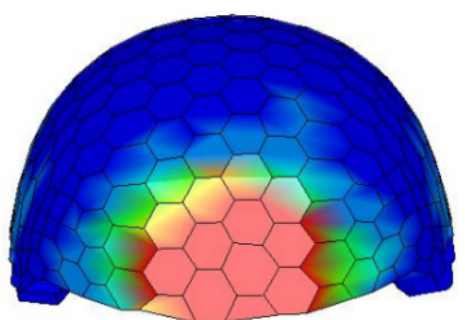

(a)

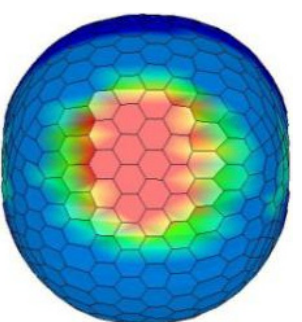

(b)

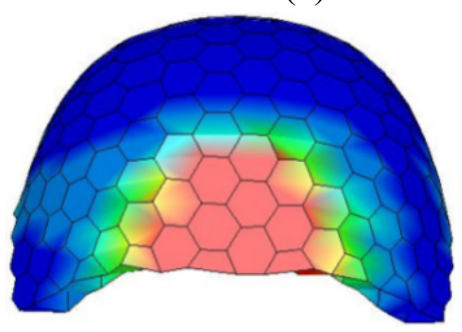

(c)

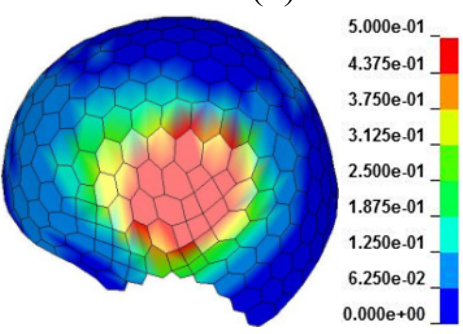

(d)

Figure 19 Von-Mises stress (MPa) contour of brain at drop height of $120 \mathrm{~cm}$ (a) Frontal (b) Vertex (c) Occipital (d) Parietal

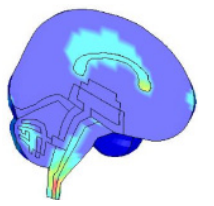

(a)

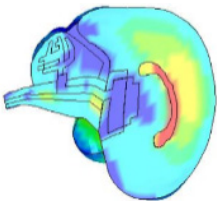

(b)

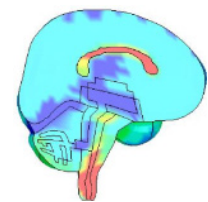

(c)

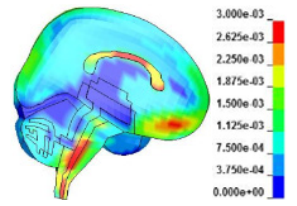

(d)

Figure 20 Shear stress (MPa) contour of brain at drop height of $120 \mathrm{~cm}$ (a) Frontal (b) Vertex (c) Occipital (d) Parietal

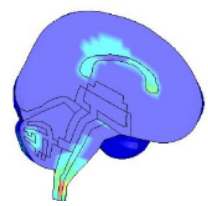

(a)

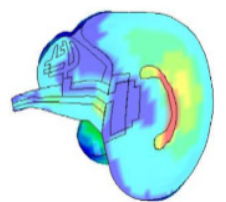

(b)

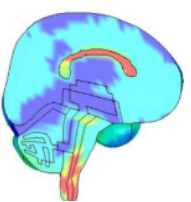

(c)

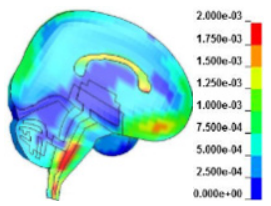

(d) 
Biomechanical performance of a bicycle helmet design

Table 4 The acceleration and contact force responses of head

\begin{tabular}{llcccc}
\hline \multicolumn{1}{c}{ Head } & & Frontal & Vertex & Occipital & Parietal \\
\hline Peak linear & Honeycomb helmet & 152.7 & 158.4 & 144.3 & 161.8 \\
acceleration (g) & No helmet & 212.7 & 160.7 & 205.2 & 185.7 \\
\hline \multirow{2}{*}{ Contact force (N) } & Honeycomb helmet & 6404 & 5823 & 5677 & 6270 \\
& No helmet & 8127 & 6158 & 7859 & 7115 \\
\hline
\end{tabular}

\section{Discussion}

A previous developed and validated $6 \mathrm{YO}$ child head model was used to investigate the injury protection performance between EPS foam helmet and paperboard helmets through frontal drop simulation. The results showed that the EPS foam helmet can effectively resist external shocks in a short time, resulting in smaller deformation. However, the biomechanical responses, in terms of Von-Mises stresses and shear stresses of the brain, were significantly reduced when the head model used the honeycomb paperboard helmet, which shows that the honeycomb paperboard helmet can provide better cushioning performance for the head. Based on the drop test of the head-helmet model, the effects of honeycomb paperboard thickness and paper material properties on the helmet protection efficiency were investigated. The results showed that the cushioning of the paperboard helmet is sensitive to the honeycomb thickness. The compression of the helmet is inversely proportional to the thickness of the helmet. Brain stress distributions were largely similar in the cerebrum with large intracranial pressure and Von-Mises stress occurring in the impact region and brainstem. Similarly, the elastic modulus of paperboard has a great influence on the cushioning of the helmet. Specifically, the stress distributions of the brain remained similar when elastic modulus of paperboard was reduced. However, when the elastic modulus exceeded $5 \mathrm{E}$ and $10 \mathrm{E}$, changes in intracranial pressure and Von-Mises stress were significant. Brain stress distributions dramatically differed in the cerebrum with a high value occurring in the corpus callosum.

The protective effect of honeycomb paperboard helmet on four falling parts of 6YO child head was analysed when the head fell from bicycle to the ground. Compared with the results of head drop test without a helmet, the biomechanical response of the head is dramatically reduced when using the paperboard helmet model, indicating that the honeycomb paperboard riding helmet can effectively resist external shocks when the head falls during accident.

\section{Conclusion}

This study is the first proposal to use corrugated and honeycomb structures in cushioning with paperboard to produce safety helmets for children's bike riding. The practicability and protective performance of paperboard helmet has been analysed. Results showed that the honeycomb/corrugated paperboard helmet also has acceptable injury protection performance while its manufacturing materials are more environmentally friendly. 


\section{Acknowledgement}

This work is financially supported by the National Nature Science Foundation of China (Grant No. 81471274).

\section{References}

CDC (2003) National centre for injury prevention and control traumatic brain injury facts. Available online at: http://www.cdc.gov/ncipc/factsheets/tbi.htm

Cernicchi, A., Galvanetto, U. and Iannucci, L. (2008) 'Virtual modelling of safety helmets: practical problems[J]', International Journal of Crashworthiness, Vol. 13, No. 4, pp.451-467.

Coats, B., Margulies, S.S. and Ji, S. (2007) 'Parametric study of head impact in the infant [J]', Stapp Car Crash Journal, Vol. 51, pp.1-15.

Cui, S., Chen, Y. and Li, H. et al. (2015) 'Development, validation and parametric study of a 3-year-old child head finite element model[J]', 3d Research, Vol. 6, No. 4, pp.1-10.

Davis, M.T., Loyd, A.M. and Shen, H.Y.H. et al. (2012) 'The mechanical and morphological properties of 6 year-old cranial bone[J]', Journal of Biomechanics, Vol. 45, No. 15, pp.2493-2498.

Fernandes, F.A.O., Willinger, R. and Deck, C. (2013) 'Finite element analysis of helmeted impacts and head injury evaluation with a commercial road helmet', IRCOBI Conference, International Research Council on the Biomechanics of Injury (IRCOBI), Gothenburg, Sweden.

Ghajari, M., Deck, C., Galvanetto, U., Iannucci, L. and Willinger, R. (2009) 'Development of numerical models for the investigation of motorcyclists accidents', Proceedings of the 7th European LS-DYNA Conference, pp.1-10.

Hernandez, F., Wu, L.C. and Yip, M.C. et al. (2016) 'Erratum to: six degree-of-freedom measurements of human mild traumatic brain injury[J]', Annals of Biomedical Engineering, Vol. 44, No. 3, pp.828-829.

Hyde, P., Eddie, M. and Langford, E. (2014) 'The acute management of children's brain injuries[J]', Paediatrics and Child Health, Vol. 24, No. 10, pp.452-456.

Iwamoto, M., Nakahira, Y. and Kimpara, H. (2015) 'Development and validation of the total HUman model for safety (THUMS) toward further understanding of occupant injury mechanisms in precrash and during crash[J]', Journal of Crash Prevention and Injury Control, Vol. 16, No. (Sup 1), pp.536-548.

Ji, S. and Zhao, W. (2015) 'A pre-computed brain response atlas for instantaneous strain estimation in contact sports[J]', Annals of Biomedical Engineering, Vol. 43, No. 8, pp.1877-1895.

Ji, S., Zhao, W. and Li, Z. et al. (2014) 'Head impact accelerations for brain strain-related responses in contact sports: a model-based investigation[J]', Biomechanics and Modeling in Mechanobiology, Vol. 13, No. 5, pp.1121-1136.

Klinich, K.D., Hulbert, G.M. and Schneider, L.W. (2002) 'Estimating infant head injury criteria and impact response using crash reconstruction and finite element modelling [J]', Stapp Car Crash Journal, Vol. 46, pp.165-194.

Li, Z., Han, X. and Ge, H. et al. (2016) 'A semi-automatic method of generating subject-specific pediatric head finite element models for impact dynamic responses to head injury[J]', Journal of the Mechanical Behavior of Biomedical Materials, Vol. 60, pp.557-567.

Li, Z., Hu, J. and Reed, M.P. et al. (2013b) 'Development, validation, and application of a parametric pediatric head finite element model for impact simulations[J]', Annals of Biomedical Engineering, Vol. 41, No. 1, pp.215-220.

Li, Z., Liu, W. and Zhang, J. et al. (2015) 'Prediction of skull fracture risk for children 0-9 months old through validated parametric finite element model and cadaver test reconstruction[J]', International Journal of Legal Medicine, Vol. 129, No. 5, pp.1055-1066. 
Li, Z., Luo, X. and Zhang, J. (2013a) 'Development/global validation of a 6-month-old pediatric head finite element model and application in investigation of drop-induced infant head injury[J]', Comput Methods Programs Biomed, Vol. 112, No.3, pp.309-319.

Mäkelä, P. and Östlund, S. (2003) 'Orthotropic elastic-plastic material model for paper materials[J]', International Journal of Solids and Structures, Vol. 40, No. 21, pp.5599-5620.

Mcpherson, G.K. and Kriewall, T.J. (1980) 'The elastic modulus of fetal cranial bone: a first step towards an understanding of the biomechanics of fetal head molding[J]', Journal of Biomechanics, Vol. 13, No. 1, pp.9-16.

Mills, N.J. and Gilchrist, A. (2008) 'Finite-element analysis of bicycle helmet oblique impacts', International Journal of Impact Engineering, Vol. 35, No. 9, pp.1087-1101.

Roth, S., Raul, J-H. and Ludes, B. et al. (2007) 'Finite element analysis of impact and shaking inflicted to a child[J]', International Journal of Legal Medicine, Vol. 121, No. 3, pp.223-228.

Ruan, S.J., Li, P.D. and Li, H.Y. et al. (2012) 'Development and validation of a 6-year-old child finite element head model[J]', Chinese Journal of Biomedical Engineering, Vol. 31, No. 4, pp.502-506.

Sevagan, G., Zhu, F. and Jiang, B. et al. (2013) 'Numerical simulations of the occupant head response in an infantry vehicle under blunt impact and blast loading conditions[J]', Proceedings of the Institution of Mechanical Engineers, Part H: Journal of Engineering in Medicine, Vol. 227, No. 7, pp.778-787.

Takhounts, E.G., Ridella, S.A. and Hasija, V. et al. (2008) 'Investigation of traumatic brain injuries using the next generation of simulated injury monitor (SIMon) finite element head model[J]', Stapp Car Crash Journal, Vol. 52, pp.1-31.

Yuping, D. (2014) Cushioning Characteristics Analysis and Optimization of Some Cushioning Package Based on ANSYS/LS-DYNA, Wu Xi, Jiangnan University.

Zhou, Z., Jiang, B. and Cao, L. et al. (2016) 'Numerical simulations of the 10-year-old head response in drop impacts and compression tests[J]', Computer Methods and Programs in Biomedicine, Vol. 131, No. C, pp.13-25. 